\title{
Research on Predicting the Rutting of Asphalt Pavement Based on a Simplified Burgers Creep Model
}

\author{
Gao Lian-sheng, Dan Han-cheng, and Chen Jia-qi \\ School of Civil Engineering, Central South University, No. 22 Shaoshan South Road, Central South University Railway Campus, \\ Changsha, Hunan Province, China
}

Correspondence should be addressed to Dan Han-cheng; danhancheng@csu.edu.cn

Received 8 June 2017; Accepted 31 July 2017; Published 12 September 2017

Academic Editor: Anna Vila

Copyright (C) 2017 Gao Lian-sheng et al. This is an open access article distributed under the Creative Commons Attribution License, which permits unrestricted use, distribution, and reproduction in any medium, provided the original work is properly cited.

Rutting is one of the most important distresses for asphalt pavement structures especially due to the heavy traffic loadings. In this paper, the solution of Burgers model is employed and simplified, which makes the residual strain only depend on the applied load. Then, the governing equation for dynamic response of pavement was established and a semianalytical solution related to the stress state of asphalt pavement was obtained. Further, an explicit expression was presented and validated to calculate rutting depth of asphalt pavement through incorporating the dynamic stress solution, simplified Burgers model solution, and time hardening model. Compared with the FEM method, the calculation error is less than 5\%, which proved the method proposed to be feasible. Compared with the numerical simulation method, every derivation of the rutting formula in this paper has the clear physical meaning and is hence easy to be understood. Besides, the proposed method can save a significant amount of time consumed due to its fast and reliable calculation.

\section{Introduction}

Rutting is one of the most important distresses for asphalt pavement structures. It is caused by material consolidation and lateral movement due to repeated heavy wheel loadings on the various pavement structures. The distress is manifested by a depressed rut along the wheel path on the pavement surface. The rutting distress is viewed as not a structure failure but as a serious safety hazard to vehicles because hydroplaning can occur in the presence of rutting in rainy weather, resulting in serious traffic accidents $[1,2]$. Moreover, vehicles tend to be pulled towards the rut path, making it difficult to drive. With the increase of road grade, construction of high-grade highways, improvement of traffic management, and emergence of channel traffic, rutting has become a critical issue for the design, construction, and use of asphalt pavement structure. Therefore, in addition to the high-temperature stability of asphalt mixtures, there currently is an urgent problem to be solved in the design, that is, how to predict the rutting of asphalt pavement structure from the mechanical properties of asphalt mixtures $[3,4]$.
Currently, a large number of indoor and outdoor studies on the rutting problem have been carried out by the international researchers. Many methods have been presented in the pursuit of a perfect design for asphalt pavement structure. In the earliest considerations of rutting in road design, the vertical strain on the top of the subgrade was limited to constrain the rutting $[5,6]$. Those methods lacked a comprehensive approach and there was no direct analysis of the asphalt pavement layer, which has the largest effect on rutting depth. Some researchers performed creep experiments on asphalt pavement and studied the experimental data to analyze the rutting of asphalt pavement [7-13]. Although many indoor experiments had been conducted to simulate a real vehicleroad system under the experimental conditions such as environment and applied load, there are significant differences in the load system and the environment conditions between the indoor experiments and those encountered in practice. Due to the limitations of the experimental methods and simulation technologies, it is difficult to simulate the outdoor environment and the mechanical load effect. Hence, predictions of rutting from indoor experiments are still different from the 
actual deformation due to rutting. Some scholars studied the rutting of asphalt pavement through rutting experiments on asphalt pavement and analysis of the experimental data [14]. The experimental methods are relatively intuitive and provide a good analogy of the rutting formation process of asphalt pavement. High-precision experimental equipment is not required. The operation methods are not complicated and are easily used in engineering. However, there are a few disadvantages of this method. The basic mechanical parameters of the materials cannot be obtained, the method cannot fully reflect the actual road performance of a structure or material, and the experimental results cannot be used for theoretical calculations in pavement design. Software using the finite element method (FEM) was also used to predict the rutting of highway pavement $[4,15-18]$. The results have been widely accepted. However, FEM software calculations are complicated and time-consuming as it is necessary to divide the domain into cells and the number of cells affects the results of the calculation. Ramsamooj et al. [19] studied the plastic strain of asphalt pavement and used it to calculate rutting depth. Lu and Sun [20] researched rutting damage of the semirigid base layer of asphalt pavement in China. They analyzed the formation mechanism of the rutting and the main factors of rutting. With a semiempirical and semitheoretical analysis method, a predictive model was built for the rutting and was found to be suitable for the semirigid base layer of asphalt pavement used in China. They considered the overall effect of the pavement structure in the semiempirical and semitheoretical analysis method. In comparison with the empirical method, their method reduced some limitations on the scope of use to a certain extent. However, their formula is still characterized by poor extrapolation. In addition, the application of mechanical theory in their work is not reasonable. Hence, there are still many difficulties in the application of this model.

It is well known that the Burgers model is well suited to simulate the viscoelastic mechanical behavior of an asphalt mixture [21]. The analytical solution of the creeping governing equation has been obtained. In the Burgers model, the strain is a function of the loading stress and loading time $t_{0}$, while the recovery strain is a function of time. When the time $t$ tends to infinity, the recovery strain can be fully recovered accordingly. Then, the recovery strain depends only on the load stress. The residual strain is obtained by subtracting the recovery strain from the strain. When the load time $t_{0}$ is fixed, the residual strain depends only on the load stress. The residual strain can then be obtained by substituting the solved load stress into the simplified Burgers model. Hence, the premise is to obtain the residual deformation of the pavement by calculating the stress distribution of the load. The residual deformation of the pavement can then be obtained by using the analytical solution of the Burgers model.

In this work, depending on the characteristics of the semirigid base layer of asphalt pavement, a governing equation of the dynamic pavement response was established based on the theory of viscoelastic layered systems and the constitutive equation of soil. Based on the boundary conditions of the related hypotheses and the continuity of displacement and stress, the stress field distribution of asphalt pavement was obtained from the analytical solution of the governing

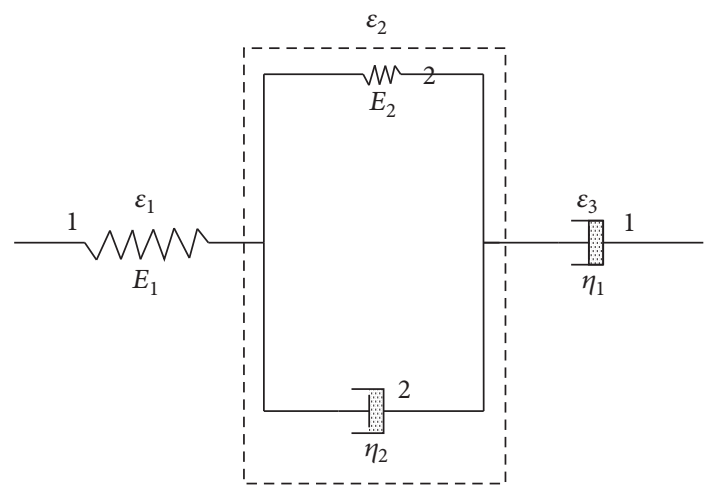

FIGURE 1: Schematic of the Burgers model with dashpot and spring components.

equation [22]. Then, the solution of the Burgers model was simplified to calculate the residual strain. Meanwhile, a time hardening model for the asphalt pavement was introduced to define a predictive formula for rutting under multiple repeating loads. The accuracy of the model was verified by comparing the results from a numerical simulation with those from analysis software.

\section{Simplification of the Burgers Model Solution}

Asphalt mixture is a kind of heat-flow material. In order to describe the thermal rheological properties of asphalt mixtures, Saboo and Kumar [23] applied the rheology theory for studying the dry and elastic characteristics of asphalt concrete. The Burgers model was proven to be suitable for analyzing the viscoelastic properties of asphalt mixtures [21] (Figure 1).

The deformation in the Burgers model includes three parts, namely, elastic deformation, viscous flow, and viscoelastic deformation (Figure 1).

The constitutive equation of the Burgers model is given by

$$
\sigma+\left(\frac{\eta_{1}}{E_{1}}+\frac{\eta_{1}+\eta_{2}}{E_{2}}\right) \dot{\sigma}+\frac{\eta_{1} \eta_{2}}{E_{1} E_{2}} \ddot{\sigma}=\eta_{1} \dot{\varepsilon}+\frac{\eta_{1} \eta_{2}}{E_{2}} \ddot{\varepsilon}
$$

Equation (1) can be rewritten as

$$
\begin{aligned}
\sigma+p_{1} \dot{\sigma}+p_{2} \ddot{\sigma} & =q_{1} \dot{\varepsilon}+q_{2} \ddot{\varepsilon} \\
p_{1} & =\frac{\eta_{1}}{E_{1}}+\frac{\eta_{1}+\eta_{2}}{E_{2}} ; \\
p_{2} & =\frac{\eta_{1} \eta_{2}}{E_{1} E_{2}} ; \\
q_{1} & =\eta_{1} ; \\
q_{2} & =\frac{\eta_{1} \eta_{2}}{E_{2}} .
\end{aligned}
$$

Equation (2) is the constitutive equation of the Burgers model. It stands for a four-parameter fluid and can be used to 


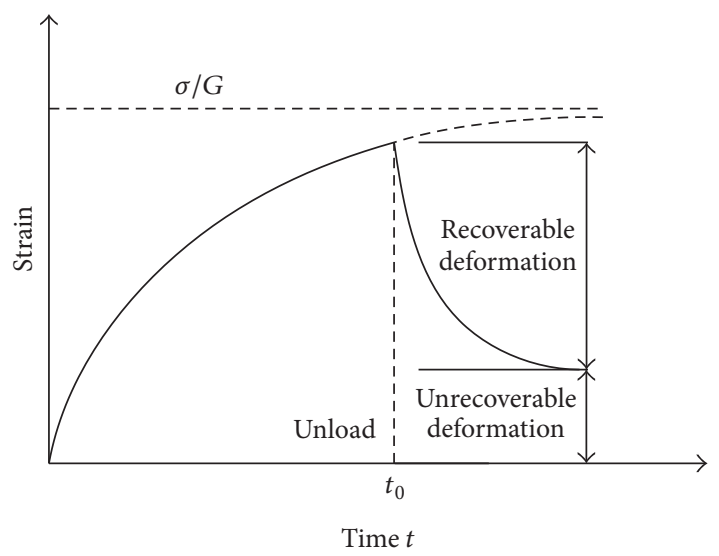

FIGURE 2: Viscoelastic creeping and recovery curves.

describe the viscoelastic behavior of materials. This equation can be used to describe the initial two stages in a material's creep curve.

The strain-time curve of Burgers model is shown in Figure 2 at $t=0$, a constant stress $\sigma_{0}$ is suddenly applied and maintained in place. The resulting strain can be obtained from the following:

$$
\gamma(t)=\sigma_{0}\left\{\frac{1}{E_{1}}+\frac{t}{\eta_{1}}+\left(\frac{1}{E_{2}}\right)\left[1-\exp \left(\frac{-t}{\lambda_{2}}\right)\right]\right\},
$$

where $\lambda_{2}=\eta_{2} / E_{2}$.

If the load is removed at $t=t_{0}$, the recovery strain $\varepsilon_{r}(t)$ is

$\varepsilon_{r}(t)$

$$
=\sigma_{0}\left\{\frac{t_{0}}{\eta_{1}}-\left(\frac{1}{E_{2}}\right)\left[\exp \left(\frac{-t}{\lambda_{2}}\right)\right]\left[1-\exp \left(\frac{-t_{0}}{\lambda_{2}}\right)\right]\right\},
$$

where $\lambda_{2}=\eta_{2} / E_{2}$.

For a highway, the time during which a car passes a certain location $t_{0}$ is very short. The interval between two cars passing by the same point is relatively larger than $t_{0}$. Equation (5) can then be simplified by letting $t \rightarrow \infty$ to completely recover the recovery strain:

$$
\varepsilon_{r}\left(t_{\infty}\right)=\frac{\sigma_{0} t_{0}}{\eta_{1}}
$$

The residual strain can then be determined by

$$
\begin{aligned}
& \Delta \varepsilon=\gamma\left(t_{0}\right)-\varepsilon_{r}\left(t_{\infty}\right) \\
& =\sigma_{0}\left\{\frac{1}{E_{1}}+\frac{t_{0}}{\eta_{1}}+\left(\frac{1}{E_{2}}\right)\left[1-\exp \left(\frac{-t_{0}}{\lambda_{2}}\right)\right]\right\}-\sigma_{0} \cdot \frac{t_{0}}{\eta_{1}} \\
& =\sigma_{0}\left\{\left\{\frac{1}{E_{1}}+\frac{t_{0}}{\eta_{1}}+\left(\frac{1}{E_{2}}\right)\left[1-\exp \left(\frac{-t_{0}}{\lambda_{2}}\right)\right]\right\}-\frac{t_{0}}{\eta_{1}}\right\} .
\end{aligned}
$$

It can be seen in (7) that parameters $\eta_{1}, \eta_{2}, E_{1}, E_{2}$, and $t_{0}$ are constants. The residual strain is a function of the load stress $\sigma_{0}$. Hence, once the load stress is obtained, the residual strain can be obtained as well. In the next section, the solution of the stress of the surface layer will be illustrated.

\section{Stress State of Asphalt Pavement under Moving Traffic Load}

In this paper, the pavement system is treated as a two-dimensional, eight-layer system. The eight layers are the (upper, middle, and lower) surface layers, the (upper, middle, and lower) base layers, and the (upper and lower) subgrade. The surface layers, the base layers, and the subgrade are regarded as dry elastic media. The governing equation of the dynamic response of the pavement is established by ignoring the compressibility of the solid particles of asphalt mixture. The governing equations of the base layers and subgrade are represented by a dynamic equilibrium equation. The external load on the pavement surface is a moving bar-type load, which is used to express the moving traffic load [22]. The load expression is then converted into a Fourier calculation expression and substituted into the governing equation, which is then transformed from a partial differential equation to an ordinary differential equation for simplification. Based on the related hypotheses and the boundary conditions pertaining to the continuity of displacement and stress, the governing equation is solved with a semianalytical solution.

As shown in Figure 3, the pavement system consists of uniform elastic medium surface layers, base layers, and subgrade. The subgrade is fixed on a rigid base bed at a certain depth. Hence, the displacement at the rigid road bed is regarded as zero. Each structural layer of the pavement system is regarded as infinite laterally.

In order to establish the model of dynamic response in pavement, some assumptions are made as follows:

(1) Each structural layer of the pavement is a medium of homogeneous, isotropic, and elastic material due to the transient load in a very short time.

(2) The deformation of the asphalt concrete is very small.

(3) The aggregates in asphalt concrete is incompressible.

(4) The displacement and stress between the structural layers are continuous.

No consideration will be made of the gradual compaction process of the pavement and the shrinkage process of the pores. Without taking water into account, the following governing equations are obtained [24]:

$$
\begin{gathered}
-\frac{\partial \sigma_{x}}{\partial x}-\frac{\partial \tau_{z x}}{\partial z}=\rho_{s} \frac{\partial w_{x}}{\partial t}, \\
-\frac{\partial \tau_{x z}}{\partial x}-\frac{\partial \sigma_{z}}{\partial z}=\rho_{s} \frac{\partial w_{z}}{\partial t} .
\end{gathered}
$$

In (8), $\sigma_{x}$ and $\sigma_{z}$ are the positive stresses of the solids along the $x$ and $z$ directions, respectively (units: $\mathrm{Pa}$ ), and $\tau_{z x}$ is the shear stress along the $x-z$ plane (units: $\mathrm{Pa}$ ).

For the two-dimensional planar strain problem, the following expressions are obtained from Hooke's principle of stress and strain and the damping property of the material.

$$
\begin{aligned}
& \sigma_{x x}^{\prime}=\sigma_{x x}-\alpha p=-2 G^{*}\left(\varepsilon_{x x}+\frac{\nu \varepsilon_{v}}{1-2 \nu}\right), \\
& \sigma_{z z}^{\prime}=\sigma_{z z}-\alpha p=-2 G^{*}\left(\varepsilon_{z z}+\frac{\nu \varepsilon_{v}}{1-2 \nu}\right),
\end{aligned}
$$




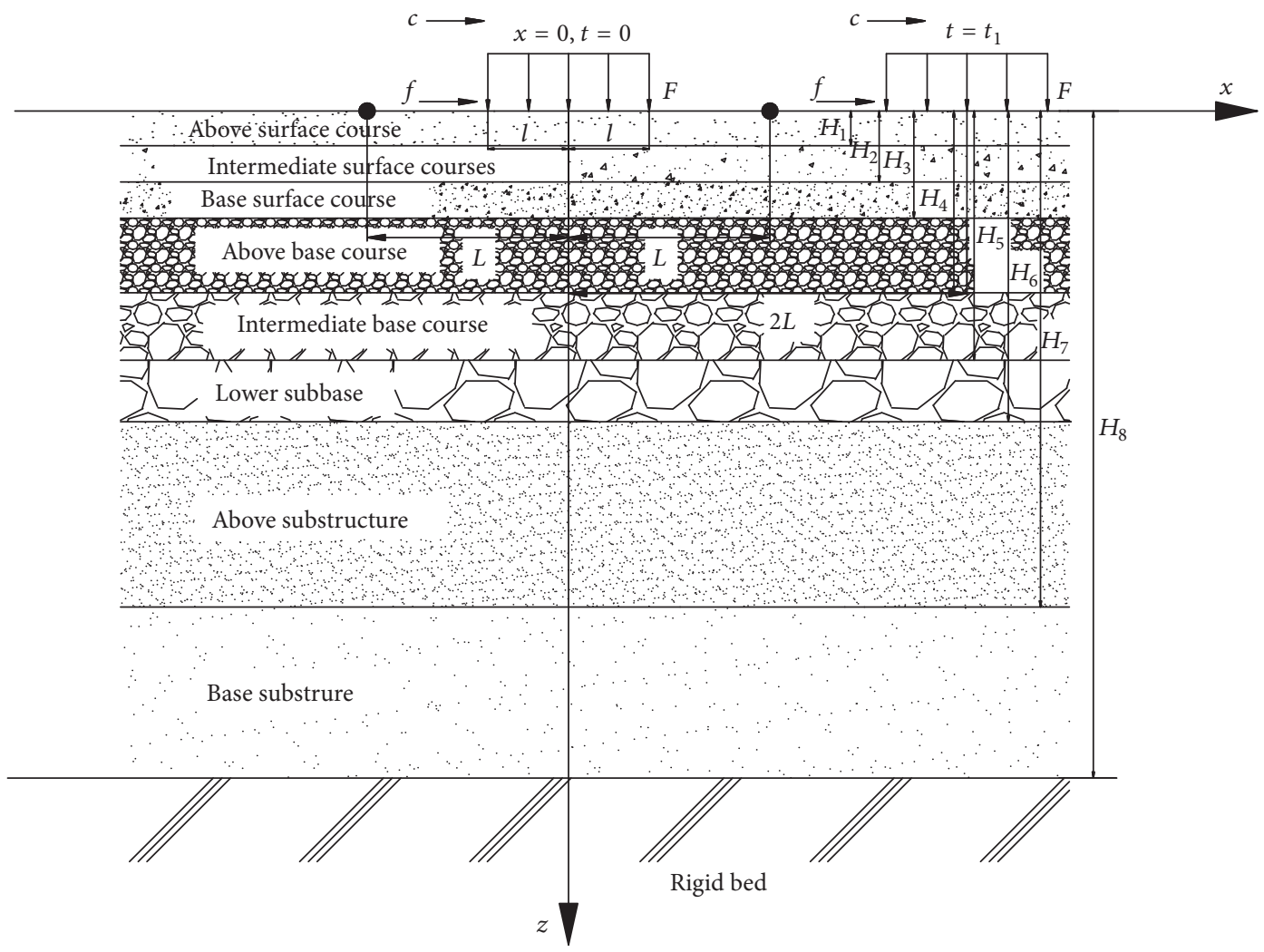

FIGURE 3: Schematic of the roadbed pavement system under the effect of a moving traffic load.

$$
\begin{aligned}
\tau_{x z} & =-2 G^{*} \varepsilon_{x z}, \\
\tau_{z x} & =-2 G^{*} \varepsilon_{z x}, \\
\varepsilon_{x x} & =\frac{\partial \zeta_{x}}{\partial x}, \\
\varepsilon_{z z} & =\frac{\partial \zeta_{z}}{\partial z}, \\
\varepsilon_{z x} & =\varepsilon_{x z}=\frac{1}{2}\left(\frac{\partial \zeta_{x}}{\partial z}+\frac{\partial \zeta_{z}}{\partial x}\right), \\
\varepsilon_{v} & =\varepsilon_{x x}+\varepsilon_{z z}, \\
G^{*} & =G(1+2 \delta i), \quad i=\sqrt{-1} .
\end{aligned}
$$

On the right side of (9), the minus sign designates that the value of a compressive stress is positive. $\sigma_{x x}^{\prime}$ and $\sigma_{z z}^{\prime}$ are the effective stresses along the horizontal $(x)$ and vertical $(z)$ directions, respectively; $\varepsilon_{x x}$ and $\varepsilon_{z z}$ are the strains along the $x$ and $z$ directions, respectively; $\zeta_{x}$ and $\zeta_{z}$ are the displacements along the $x$ and $z$ directions, respectively; $v$ is the Poisson ratio; and $G^{*}$ is the dynamic shear modulus of the solid material [25], where $\delta$ is the damping coefficient of the material, and $G$ is the static shear modulus of the solid material.

For the pavement layers, the base layers, and the subgrade, the dynamic governing equations are shown in (14), where $i$ is a layer indicator from 1 to 8 , designating the upper surface layer, the middle surface layer, the lower surface layer, the upper base layer, the middle base layer, the lower base layer, the upper subgrade, and the lower subgrade, respectively.

$$
\begin{aligned}
& \frac{2 G_{i}^{*}\left(1-v_{i}\right)}{1-2 v_{i}} \frac{\partial^{2} \zeta_{x i}}{\partial x^{2}}+\left(\frac{2 G_{i}^{*} v_{i}}{1-2 v_{i}}+G_{i}^{*}\right) \frac{\partial^{2} \zeta_{z i}}{\partial x \partial z} \\
& \quad+G_{i}^{*} \frac{\partial^{2} \zeta_{x i}}{\partial z^{2}}=\rho \frac{\partial^{2} \zeta_{x i}}{\partial t^{2}}, \\
& \frac{2 G_{i}^{*}\left(1-v_{i}\right)}{1-2 v_{i}} \frac{\partial^{2} \zeta_{z i}}{\partial z^{2}}+\left(\frac{2 G_{i}^{*} \nu_{i}}{1-2 v_{i}}+G_{i}^{*}\right) \frac{\partial^{2} \zeta_{x i}}{\partial x \partial z} \\
& \quad+G_{i}^{*} \frac{\partial^{2} \zeta_{z i}}{\partial x^{2}}=\rho \frac{\partial^{2} \zeta_{z i}}{\partial t^{2}} .
\end{aligned}
$$

3.1. Expression of Moving Traffic Load. A moving load function $(t=0)$ may be represented with a Fourier series as follows [26, 27]:

$$
\begin{aligned}
& F(x)= \begin{cases}F & \text { for }|x|<l \\
0 & \text { for } l<|x|<L,\end{cases} \\
& F(x)=\operatorname{Re} \sum_{m=-\infty}^{\infty} F_{m} \exp \left(i \omega_{m} x\right) .
\end{aligned}
$$

In (16), the load has a width of $2 l$ and a strength of $F ; \omega_{m}=$ $2 \pi m / T$, where $T$ is the distribution period of the moving load. Here, $T=2 L$; and $m$ is a real number in the range from $-\infty$ to $+\infty$. 
When using a moving coordinate system, that is, assuming that the coordinate system moves along with the moving direction of the load, then the expression of the Fourier series of the moving load of the traffic at any moment is

$$
F(x-c t)=\operatorname{Re} \sum_{m=-\infty}^{\infty} F_{m} \exp \left[i \omega_{m}(x-c t)\right] .
$$

According to the Fourier transform, $F_{m}$ is

$$
F_{m}= \begin{cases}\frac{l}{L} F & \text { for } m=0 \\ \frac{F}{\pi m} \sin \left(\pi m \frac{l}{L}\right) & \text { for } m \neq 0\end{cases}
$$

3.2. General Solution of the Dynamic Governing Equation. For a linear system, an arbitrary function $\varphi(x, z, t)$ can be expressed as the sum of a series of linear harmonic functions [28], which can be written as

$$
\varphi(x, z, t)=\operatorname{Re} \sum_{m=-\infty}^{\infty} \Phi_{m}(z) \exp \left[i \omega_{m}(x-c t)\right]
$$

In (19), $\Phi_{m}(z)=\Phi_{m}$ is a function of the single independent variable $z$. It is an $m$ th harmonic function, while the exponential function is only a function of $x-c t$.

According to formula (19), the governing equation of the entire system can be written in the following form:

$$
\begin{aligned}
& b_{i 1} \frac{d^{2} Q_{i m}}{d z^{2}}+b_{i 2} Q_{i m}+b_{i 3} \frac{d R_{i m}}{d z}=0, \\
& c_{i 1} \frac{d^{2} R_{i m}}{d z^{2}}+c_{i 2} R_{i m}+c_{i 3} \frac{d Q_{i m}}{d z}=0 .
\end{aligned}
$$

The parameters in the above equations are $(i=1 \sim 8)$ as follows:

$$
\begin{aligned}
& b_{i 1}=G_{i}^{*}, \\
& b_{i 2}=-\left(\omega_{m}\right)^{2} \frac{2 G_{i}^{*}\left(1-v_{i}\right)}{1-2 v_{i}}+\left(\omega_{m}\right)^{2} c^{2} \rho_{s}, \\
& b_{i 3}=i \omega_{m}\left(\frac{2 G_{i}^{*} v_{i}}{1-2 v_{i}}+G_{i}^{*}\right), \\
& c_{i 1}=\frac{2 G_{i}^{*}\left(1-v_{i}\right)}{1-2 v_{i}}, \\
& c_{i 2}=-w_{m}^{2} G_{i}^{*}+w_{m}^{2} c^{2} \rho_{s}, \\
& c_{i 3}=i \omega_{m}\left(\frac{2 G_{i}^{*} v_{i}}{1-2 v_{i}}+G_{i}^{*}\right), \\
& G_{i}^{*}=G_{i}(1+2 \delta i) .
\end{aligned}
$$

The general solution of the governing equation may be expressed as follows:

$$
\begin{aligned}
Q_{i m} & =\sum_{j=1}^{4} A_{i j m} \exp \left(q_{i j} z\right), \\
R_{i m} & =\sum_{j=1}^{4} r_{i j} A_{i j m} \exp \left(q_{i j} z\right) .
\end{aligned}
$$

After simplification,

$$
\begin{gathered}
\sum_{j=1}^{4}\left[b_{i 1}\left(q_{i j}\right)^{2}+b_{i 2}+b_{i 3} r_{i j} q_{i j}\right] A_{i j m}=0, \\
\sum_{j=1}^{4}\left[c_{i 1} r_{i j}\left(q_{i j}\right)^{2}+c_{i 2} r_{i j}+c_{i 3} q_{i j}\right] A_{i j m}=0,
\end{gathered}
$$

where $r_{i j}=-\left(b_{i 1}\left(q_{i j}\right)^{2}+b_{i 2}\right) / q_{i j} b_{i 3}$, and $q_{i j}(j=1 \sim 4)$ are the roots of the 4 th-order polynomials in

$$
b_{i 1} c_{i 1}(q)^{4}+\left(b_{i 2} c_{i 2}-b_{i 3} c_{i 3}+b_{i 1} c_{i 2}\right)(q)^{2}+b_{i 2} c_{i 2}=0 .
$$

The solutions (roots) can be obtained through numerical methods (e.g., MATLAB program).

Boundary Conditions and Solution. In order to solve the governing equation, it is necessary to obtain the integration constant $A_{i j m}(i=1 \sim 8, j=1 \sim 4)$.

At the top of the upper surface layer $(z=0), \tau_{1 x z}=0$, $\sigma_{1 z}=F$.

At the bottom of the upper surface layer $\left(z=H_{1}\right)$, the boundary condition of the displacement is $\zeta_{1 x}=\zeta_{1}$ and $\xi_{1 z}=$ $\zeta_{2}$. Then, the group of equations for the boundary condition can be written as

$$
\sum_{j=1}^{4}\left(q_{1 j}+i \omega_{m} r_{1 j}\right) A_{1 j m}=0
$$$$
\sum_{j=1}^{4}\left[-\left(2 G_{1}^{*} \frac{1-\nu_{1}}{1-2 \nu_{1}}\right) q_{1 j} r_{1 j}-\left(i \omega_{m}\right)\left(2 G_{1}^{*} \frac{\nu_{1}}{1-2 \nu_{1}}\right)\right]
$$

$$
\begin{aligned}
& \cdot A_{1 j m}=F_{m}, \\
& \sum_{j=1}^{4} A_{1 j m} \exp \left(q_{1 j} H_{1}\right)=\zeta_{1}, \\
& \sum_{j=1}^{4} r_{1 j} A_{1 j m} \exp \left(q_{1 j} H_{1}\right)=\zeta_{2}, \\
& \sum_{j=1}^{4}\left[-\left(2 G_{1}^{*} \frac{1-v_{1}}{1-2 v_{1}}\right) q_{1 j} r_{1 j}-\left(i \omega_{m}\right)\left(2 G_{1}^{*} \frac{v_{1}}{1-2 v_{1}}\right)\right] \\
& \cdot A_{1 j m} \exp \left(q_{1 j} H_{1}\right)=\sigma_{H_{1}}, \\
& \sum_{j=1}^{4} G_{1}^{*}\left(q_{1 j}+i \omega_{m} r_{1 j}\right) A_{1 j m} \exp \left(q_{1 j} H_{1}\right)=\chi_{H_{1}} \cdot
\end{aligned}
$$


The boundary conditions for the middle surface layer, the lower surface layer, the upper base layer, the middle base layer, the lower base layer, and the upper subgrade $(i=2 \sim 7)$ are

$$
\begin{aligned}
& \sum_{j=1}^{4} A_{i j m} \exp \left(q_{i j} H_{i-1}\right)=\zeta_{i-1}, \\
& \sum_{j=1}^{4} r_{i j} A_{i j m} \exp \left(q_{i j} H_{i-1}\right)=\zeta_{i}, \\
& \sum_{j=1}^{4} G_{i}^{*}\left(q_{i j}+i \omega_{m} r_{i j}\right) A_{i j m} \exp \left(q_{i j} H_{i-1}\right)=\chi_{H_{i-1}}, \\
& \sum_{j=1}^{4}\left[-\left(2 G_{i}^{*} \frac{1-v_{i}}{1-2 v_{i}}\right) q_{i j} r_{i j}-\left(i \omega_{m}\right)\left(2 G_{i}^{*} \frac{v_{i}}{1-2 v_{i}}\right)\right] \\
& \cdot A_{i j m} \exp \left(q_{i j} H_{i-1}\right)=\sigma_{H_{i-1}}, \\
& \sum_{j=1}^{4} A_{i j m} \exp \left(q_{i j} H_{i}\right)=\zeta_{i+1}, \\
& \sum_{j=1}^{4} r_{i j} A_{i j m} \exp \left(q_{i j} H_{i}\right)=\zeta_{i+2}, \\
& \sum_{j=1}^{4} G_{i}^{*}\left(q_{i j}+i \omega_{m} r_{i j}\right) A_{i j m} \exp \left(q_{i j} H_{i}\right)=\chi_{H_{i}}, \\
& \sum_{i j m} \exp \left(q_{i j} H_{i}\right)=\sigma_{H_{i}} \cdot \\
& \left.\left.\sum_{i j}^{*} \frac{1-v_{i}}{1-2 v_{i}}\right) q_{i j} r_{i j}-\left(i \omega_{m}\right)\left(2 G_{i}^{*} \frac{v_{i}}{1-2 v_{i}}\right)\right]
\end{aligned}
$$

In the lower subgrade model, the boundary conditions are listed as follows.

At the interface between the lower subgrade and upper subgrade $\left(z=H_{7}\right)$, the boundary conditions for the displacements are $\xi_{x}=\zeta_{71}, \xi_{z}=\zeta_{72}$.

At the interface between the lower subgrade and upper subgrade $\left(z=H_{7}\right)$, the boundary conditions for the stress are $\tau_{x z}=\chi_{H 7}, \sigma_{z}\left(H_{4}\right)=\sigma_{H 7}$.

At the bottom of the lower subgrade $\left(z=H_{8}\right)$, the boundary conditions of the displacements are $\zeta_{x}=0, \zeta_{z}=0$.
Then, a group of equations for the corresponding boundary conditions can be written as

$$
\begin{aligned}
& \sum_{j=1}^{4} A_{8 j m} \exp \left(q_{8 j} H_{7}\right)=\zeta_{71}, \\
& \sum_{j=1}^{4} r_{8 j} A_{8 j m} \exp \left(q_{8 j} H_{7}\right)=\zeta_{72}, \\
& \sum_{j=1}^{4} G_{8}^{*}\left(q_{8 j}+i \omega_{m} r_{8 j}\right) A_{8 j m} \exp \left(q_{8 j} H_{7}\right)=\chi_{H_{7}}, \\
& \sum_{j=1}^{4}\left[-\left(2 G_{8}^{*} \frac{1-v_{8}}{1-2 \nu_{8}}\right) q_{8 j} r_{8 j}-\left(i \omega_{m}\right)\left(2 G_{8}^{*} \frac{v_{8}}{1-2 v_{8}}\right)\right] \\
& \sum_{j=1}^{4} A_{8 j m} \exp \left(q_{8 j} H_{8}\right)=0, \\
& \sum_{j=1}^{4} r_{8 j} A_{8 j m} \exp \left(q_{8 j} H_{7}\right)=\sigma_{H_{7}}, \\
& \exp \left(q_{8 j} H_{8}\right)=0 .
\end{aligned}
$$

For all the groups of equations of the boundary conditions shown above, the numerical methods can be used to obtain the displacement $\left(\delta_{i x}\right.$ and $\left.\delta_{i y}\right)$, the positive stress $\left(\sigma_{H i}\right)$, and the shear stress $\left(\chi_{H_{i}}\right)$. These solutions can then be substituted into the general expressions for the corresponding dynamic governing equations of the pavement system under a moving load. The solutions for the displacements can be expressed as the following form:

$$
\begin{aligned}
& \xi_{i x}(x, z, t)=\operatorname{Re} \sum_{m=-\infty}^{\infty}\left[\sum_{j=1}^{4} A_{i j m} \exp \left(q_{i j} z\right)\right] \\
& \cdot \exp \left[i \omega_{m}(x-c t)\right] \\
& \xi_{i z}(x, z, t)=\operatorname{Re} \sum_{m=-\infty}^{\infty}\left[\sum_{j=1}^{4} r_{i j} A_{i j m} \exp \left(q_{i j} z\right)\right] \\
& \cdot \exp \left[i \omega_{m}(x-c t)\right] .
\end{aligned}
$$

In addition, the expressions of the shear stress and the positive stress are

$$
\begin{aligned}
& \tau_{i x z}(x, z, t)=-\operatorname{Re} \sum_{m=-\infty}^{\infty}\left[\sum_{j=1}^{4} G_{i}^{*}\left(q_{i j}+i \omega_{m} r_{i j}\right) A_{i j m} \exp \left(q_{i j} z\right)\right] \exp \left[i \omega_{m}(x-c t)\right] \\
& \sigma_{i z}(x, z, t)=\operatorname{Re} \sum_{m=-\infty}^{\infty}\left\{\sum_{j=1}^{4}\left[-\left(2 G_{i}^{*} \frac{1-v_{i}}{1-2 v_{i}}\right) q_{i j} r_{i j}-i \omega_{m}\left(2 G_{i}^{*} \frac{v_{i}}{1-2 v_{i}}\right)\right] A_{i j m} \exp \left(q_{i j} z\right)\right\} \exp \left[i \omega_{m}(x-c t)\right], \\
& \sigma_{i x}(x, z, t)=\operatorname{Re} \sum_{m=-\infty}^{\infty}\left\{\sum_{j=1}^{4}\left[-\left(2 G_{i}^{*} \frac{v_{i}}{1-2 v_{i}}\right) q_{i j} r_{i j}-i \omega_{m}\left(2 G_{i}^{*} \frac{1-v_{i}}{1-2 v_{i}}\right)\right] A_{i j m} \exp \left(q_{i j} z\right)\right\} \exp \left[i \omega_{m}(x-c t)\right] .
\end{aligned}
$$


TABLE 1: Calculation parameters of numerical example.

\begin{tabular}{lccc}
\hline $\begin{array}{l}\text { Pavement } \\
\text { structural layers }\end{array}$ & $\begin{array}{c}\text { Elastic } \\
\text { modulus } \\
(\mathrm{MPa})\end{array}$ & $\begin{array}{c}\text { Poisson's } \\
\text { ratio }\end{array}$ & $\begin{array}{c}\text { Thickness } \\
(\mathrm{cm})\end{array}$ \\
\hline $\begin{array}{l}\text { Modified asphalt } \\
\text { SMA-13 }\end{array}$ & 870 & 0.25 & 4 \\
$\begin{array}{l}\text { Modified asphalt } \\
\text { Sup-20 }\end{array}$ & 910 & 0.25 & 6 \\
$\begin{array}{l}\text { Modified asphalt } \\
\text { Sup-25 }\end{array}$ & 1031 & 0.25 & 8 \\
$\begin{array}{l}\text { Cement stabilized } \\
\text { gravel }\end{array}$ & 1200 & 0.2 & 40 \\
$\begin{array}{l}\text { Lime soil } \\
\text { Soil base }\end{array}$ & 300 & 0.3 & 20 \\
& 45 & 0.40 & 500 \\
\hline
\end{tabular}

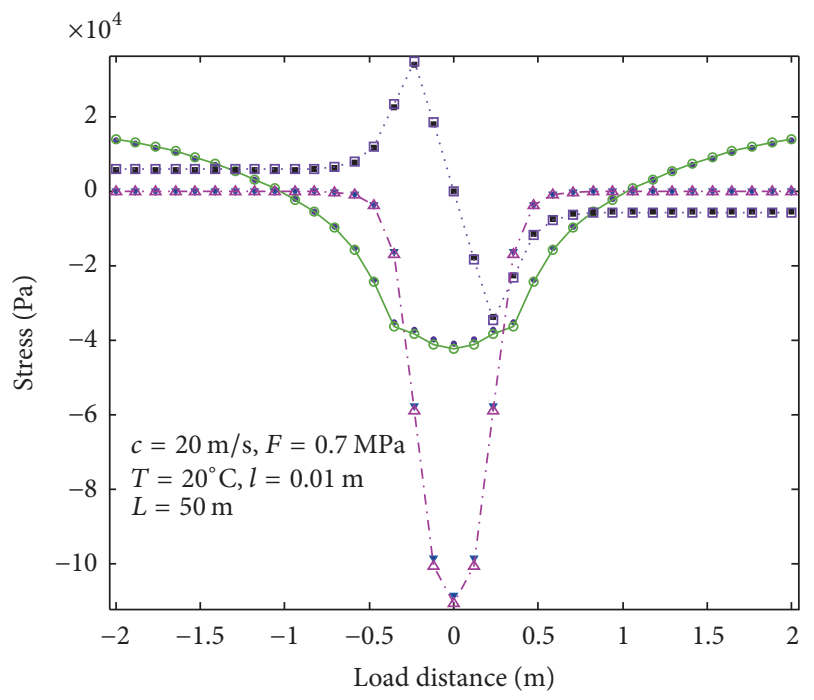

- FME, horizontal stress $\quad$.... This work, vertical stres

- This work, horizontal stress $\quad$ FME, shear stress

- FME, vertical stress $\quad-\Delta_{-}$This work, shear stress

FIGURE 4: Comparison of this work and FEM simulation.
Therefore, the stress in pavement system under moving traffic load can be expressed according to the above derivation. Further, it is significant to validate the solution of stress state in pavement which can be illustrated as follows. Here, a FEM simulation is conducted, and the calculation parameters of pavement structure are listed in Table 1 [29].

Both the proposed method and FEM simulations are used to calculate the shear stress, vertical positive stress, and horizontal positive stress at the bottom of the asphalt pavement. The comparison results are shown in Figure 4.

It can be seen in Figure 4 that the calculation results (shear stress, vertical stress, and horizontal stress) of this work excellently match that of the FEM model. Therefore, the stress obtained through the presented solution can be used to evaluate the deformation in the following analysis.

\section{Establishment of Rutting Calculation Model}

4.1. Rutting Deformation. From the obtained stress field distribution of the pavement, it can be seen that the vertical stress of the surface layer $\sigma_{z}(t)$ is a function that fluctuant periodically. The action distance (stress at the action point begins to appear within the range of $l$, as shown in Figure 3) is $l[\mathrm{~m}]$ at both sides of the observation point. The action time of the stress is $t=2 l / c$, where $c$ is the moving speed of a vehicle. During the actual action time $(t)$ which is very short, the stress $\left(\sigma_{z}(t)\right)$ is fluctuant periodically as well; nevertheless, in the solution of Burgers model, the action stress $\left(\sigma_{0}\right)$ is kept constantly during $t_{0}$ ( $t_{0}$ is load time, as shown in Figure 2$)$. Therefore, $\sigma_{z}(t)$ needed to be transformed into $\sigma_{0}$ during action time $\left(t_{0}\right)$. According to the stress equivalence principle, $\sigma_{0}$ can be given by

$$
\sigma_{0}=\frac{\int_{0}^{2 l / c} \sigma_{z}(t) d t}{t_{0}} .
$$

Substitute (32) into (7) and integrate the residual strain along the depth direction (the thickness of the surface layer) to obtain the following rutting depth for one load cycle, that is,

$$
\begin{aligned}
\mathrm{RD} & =\int_{0}^{H_{1}} \Delta \varepsilon d z=\int_{0}^{H_{1}}\left[\gamma_{1}\left(\frac{2 l}{c}\right)-\varepsilon_{r}(t)\right] d z=\int_{0}^{H_{1}}\left\{\frac{\int_{0}^{2 l / c} \sigma_{z}(t) d t}{t_{0}}\left\{\frac{1}{E_{1}}+\frac{t_{0}}{\eta_{1}}+\left(\frac{1}{E_{2}}\right)\left[1-\exp \left(\frac{-t_{0}}{\lambda_{2}}\right)\right]\right\}\right. \\
& \left.-\int_{0}^{2 l / c} \frac{\sigma(t)}{\eta_{1}} d t\right\} d z=\operatorname{Re} \sum_{m=-\infty}^{\infty}\left\{\sum_{j=1}^{4}\left\{\left[-\left(2 G_{i}^{*} \frac{1-v_{i}}{1-2 v_{i}}\right) q_{i j} r_{i j}-i \omega_{m}\left(2 G_{i}^{*} \frac{v_{i}}{1-2 v_{i}}\right)\right] A_{i j m}\left[\frac{\exp \left(q_{i j} H_{i}\right)-1}{i w_{m} c q_{i j}}\right]\right\}\right. \\
& \left.\cdot\left[\exp \left(2 i w_{m}\right)-\exp \left(-2 i w_{m}\right)\right]\right\} \cdot\left\{\frac{1 / E_{1}+t_{0} / \eta_{1}+\left(1 / E_{2}\right)\left[1-\exp \left(-t_{0} / \lambda_{2}\right)\right]}{t_{0}}-\frac{1}{\eta_{1}}\right\} .
\end{aligned}
$$

4.2. Time Hardening Model. As the axle load number and time increase, the asphalt pavement will be gradually aged, and the viscous coefficient of asphalt pavement will gradually increase [30]. That is to say, the rutting depth cannot develop at the same speed of one load cycle (33). Thus, a time hardening model is chosen for restricting the rutting increasing 
speed; that is, the coefficient of viscosity of asphalt pavement is given by

$$
\eta(n)= \begin{cases}1 & n=1 \\ 1+\sum_{t=2}^{n} \exp (B n) & n \geq 2\end{cases}
$$

where $n$ is the number of standard axle load cycles and $B$ is related to the parameters of the asphalt pavement. Then, the rutting expression under a number of load cycles can be given by

$$
\begin{aligned}
& \operatorname{RD}(n)=\operatorname{Re} \sum_{m=-\infty}^{\infty}\left\{\sum_{j=1}^{4}\left\{\left[-\left(2 G_{i}^{*} \frac{1-v_{i}}{1-2 v_{i}}\right) q_{i j} r_{i j}-i \omega_{m}\left(2 G_{i}^{*} \frac{v_{i}}{1-2 v_{i}}\right)\right] A_{i j m}\left[\frac{\exp \left(q_{i j} H_{i}\right)-1}{i w_{m} c q_{i j}}\right]\right\}\right. \\
& \left.\cdot\left[\exp \left(2 i w_{m}\right)-\exp \left(-2 i w_{m}\right)\right]\right\} \cdot\left\{\frac{1 / E_{1}+t_{0} / \eta_{1}+\left(1 / E_{2}\right)\left[1-\exp \left(-t_{0} / \lambda_{2}\right)\right]}{t_{0}}-\frac{1}{\eta_{1}}\right. \\
& \left.+\frac{1 / E_{1}+t_{0} / \eta_{1}(n)+\left(1 / E_{2}\right)\left[1-\exp \left(-t_{0} \cdot E_{2} / \eta_{2}(n)\right)\right]}{t_{0}}-\frac{1}{\eta_{1}(n)}\right\} .
\end{aligned}
$$

In (35),

$$
\eta_{1}(n)=\eta_{2}(n)= \begin{cases}1 & n=1 \\ 1+\sum_{t=2}^{n} \exp (B n) & n \geq 2\end{cases}
$$

\section{Model Validation and Parameter Analysis}

5.1. Model Validation. Results of experiments on asphalt pavement described in An's research [31] are used herein as an example to verify our analytical solution, and the FEM with ABAQUS [29] is also adopted to verify the calculation results. The parameters of elasticity and viscosity are evaluated and tabulated in Table 2 [31]. The operating temperature is $60^{\circ} \mathrm{C}$ and the corresponding deformations measured from the test, analytical method, and FEM are shown in Figure 5. Good matches can be seen between the analytical and FEM prediction and test data under the given ALN levels.

Furthermore, to extend comparison under various temperature, applied load, large axle load number, and so forth, the theoretical calculations of rutting for two kinds of pavement structures (Figures 6 and 7) are compared with the results of FEM modeling. The effects on rutting are comparatively analyzed for the factors such as the axle load number (ALN), axle load (wheel pressure), pavement temperature, and vehicle speed of vehicle.

The parameters of the asphalt mixtures in the Burgers model are shown in Table 3 [32], and the parameters of the nonasphaltic layers in this work are shown in Table 4 [32]. The results are summarized in Table 7 . For the calculations of the two kinds of asphalt pavements, the parameter of the time hardening model $(B)$ is equivalent to -0.42 ; the coefficient of rolling friction is 0.02 .

It can be seen in Table 5 and Figure 8 that the calculation results of this work agree with that of the FEM model. The slight errors may be come from the model assumption which claims that the recovery time of pavement deformation tends to be infinite. Actually, the residual strain of asphalt pavement in a finite time does not reach the final value calculated by (7). Nevertheless, the strain can almost recover at finite time. In addition, the simplification of stress equivalence based on (32) may also lead to the difference between FEM and analytical results. However, the errors of asphalt pavement rutting in the calculation example are almost below 5\%, which validates the method proposed in this paper. Furthermore, both the analytical and FEM methods are used to calculate the viscous flows in the rutting deformation of the asphalt pavement in the following analysis.

5.2. Effect of $A L N$. Figure 8(a) shows the relationship between the RD and ALN for two pavement structures. Obviously, the power function appears. That is to say, $\mathrm{RD}$ increases with ALN in a power manner. It is worth noting that the rutting depth increased rapidly with the increase of the ALN at the initial stage, and then the increase of rutting decreases sharply and gradually keeps stable at a small value. Hence, the hardening rate of pavement material is relatively larger at the initial stage of traffic on the asphalt pavement and rapidly decreases with ALN (Figure 8(b)). For instance, when the ALNs are $1.0 \times 10^{6}$ and $6.0 \times 10^{6}$, the calculated value of $\mathrm{RD}$ is approximately $3.1 \mathrm{~mm}$ and $6.4 \mathrm{~mm}$, respectively. Nearly $50 \%$ $\mathrm{RD}$ can be reached under the condition of one-sixth ALN. As far as the application is concerned, the relation between $\mathrm{RD}$ and ALN can effectively predict the trend of the rutting depth and provide the information that more attention should be paid to the early period after the pavement is opened to traffic in the preventive maintenance of the highway.

5.3. Effect of Wheel Pressure. The effect of wheel pressure on the RD is investigated, and wheel pressure varies from 0.7 $\mathrm{MPa}$ to $1.2 \mathrm{MPa}$, which are commonly applied on the asphalt pavement. The temperature is $60^{\circ} \mathrm{C}$, vehicle speed is $c=25 \mathrm{~m} / \mathrm{s}$, the coefficient of rolling friction is $\alpha=0.02$, and ALN is 1,000,000. The proposed method in this work and ABAQUS are employed to calculate RD of asphalt pavement structure A with the results shown in Table 6 and Figure 9. 
TABLE 2: Parameters of asphalt concrete for computations.

\begin{tabular}{|c|c|c|c|c|c|c|c|c|}
\hline \multirow{2}{*}{ Materials } & \multirow{2}{*}{$\begin{array}{c}\text { Operating } \\
\text { temperature } \\
\left({ }^{\circ} \mathrm{C}\right)\end{array}$} & \multirow{2}{*}{$\begin{array}{l}\text { Thickness } \\
(\mathrm{cm})\end{array}$} & \multirow{2}{*}{$\begin{array}{c}\text { Elastic } \\
\text { modulus } \\
(\mathrm{MPa})\end{array}$} & \multirow{2}{*}{$\begin{array}{c}\text { Poisson's } \\
\text { ratio }\end{array}$} & \multicolumn{4}{|c|}{ The parameters of the Burgers model } \\
\hline & & & & & $E_{1}(\mathrm{MPa})$ & $E_{2}(\mathrm{MPa})$ & $\eta_{1}(\mathrm{MPa} \cdot \mathrm{s})$ & $\begin{array}{c}\eta_{2} \\
(\mathrm{MPa} \cdot \mathrm{s})\end{array}$ \\
\hline $\begin{array}{l}\text { Asphalt } \\
\text { mixture } \\
\text { (AC-13) }\end{array}$ & 60 & 5 & 2297 & 0.48 & 301.4 & 75.63 & 8.25 & 0.15 \\
\hline
\end{tabular}

TABLE 3: Calculation parameters for asphaltic layers.

\begin{tabular}{|c|c|c|c|c|c|c|c|}
\hline Asphaltic layers & Temperature $\left({ }^{\circ} \mathrm{C}\right)$ & Elastic modulus (MPa) & Poisson's ratio & $E_{1}(\mathrm{~Pa})$ & $E_{2}(\mathrm{~Pa})$ & $\eta_{1}(\mathrm{~Pa} \cdot \mathrm{s})$ & $\eta_{2}(\mathrm{~Pa} \cdot \mathrm{s})$ \\
\hline \multirow{3}{*}{ AK-13A } & 15 & 1200 & 0.25 & 715632541 & 196358429 & 4153952 & 395846 \\
\hline & 40 & 750 & 0.35 & 68165468 & 32569834 & 712654 & 58625 \\
\hline & 60 & 710 & 0.45 & 20568462 & 24658635 & 117652 & 135264 \\
\hline \multirow{3}{*}{ AC-20C } & 15 & 1835 & 0.25 & 240243999 & 87373286 & 1757472 & 184406 \\
\hline & 40 & 1200 & 0.35 & 37986096 & 22331739 & 337760 & 30151 \\
\hline & 60 & 760 & 0.45 & 15528434 & 17425937 & 89503 & 51975 \\
\hline \multirow{3}{*}{ AC-20F } & 15 & 1800 & 0.25 & 235872362 & 83256421 & 1732541 & 182361 \\
\hline & 40 & 1100 & 0.35 & 33562418 & 20562416 & 315632 & 28542 \\
\hline & 60 & 740 & 0.45 & 15325165 & 16325612 & 86853 & 48682 \\
\hline
\end{tabular}

TABLE 4: Calculation parameters for nonasphaltic layers.

\begin{tabular}{lcc}
\hline Pavement structure layers & Elastic modulus (MPa) & Poisson's ratio \\
\hline Cement-stabilized gravel & 1500 & 0.25 \\
Lime-fly-ash gravel & 1400 & 0.25 \\
Lime soil & 550 & 0.35 \\
Soil base & 48 & 0.40 \\
\hline
\end{tabular}

From Table 6 and Figure 9, it can be seen that the RDs predicted by these two methods match well, and the maximum error is less than $5 \%$. The $\mathrm{RD}$ has an approximately linear relationship with the wheel pressure. Significantly, The $\mathrm{RD}$ value seems sensitive to the wheel pressure. For instance, the value of RD linearly changes from $8.52 \mathrm{~mm}$ to $23.04 \mathrm{~mm}$ when the wheel pressure ranges from $0.7 \mathrm{MPa}$ to $1.2 \mathrm{MPa}$. That is to say, the magnitude of RD will grow up with $170 \%$ when wheel pressure increases with $71 \%$. It should be point out that this kind of increasing relationship is only based on the rutting analysis for the given parameters. It does not mean that the RD will increase to an unlimited value for a large wheel pressure because the asphalt pavement will fail. Furthermore, the result indicates that the heavy traffic load (wheel pressure) will expedite formation of asphalt pavement rutting. In the design stage of the highway pavement, the effect of overload on the pavement surface should be considered in terms of heavy haul vehicles.

5.4. Effect of Pavement Temperature. As we know, temperature is a very significant factor which plays a role in affecting rutting deformation. It is mainly because the properties of asphalt pavement partly, especially the viscoelasticity parameters, depend on the environmental and pavement temperature (Asi, 2007; Motamed and Bahia, 2011). For example, the elastic modulus $\left(E_{1}, E_{2}\right)$ and viscosity coefficient

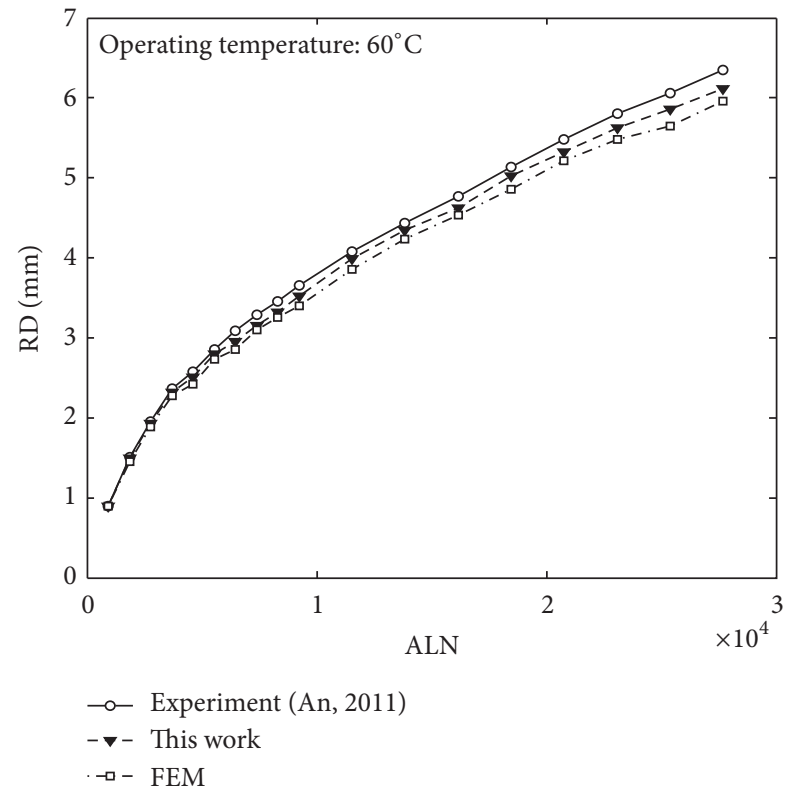

FIGURE 5: RD of asphalt pavement for comparison.

$\left(\eta_{1}\right)$ of asphalt pavement will decrease with the temperature increasing. Therefore, the effect of pavement temperature on $\mathrm{RD}$ is conducted. For vehicle speed of $c=25 \mathrm{~m} / \mathrm{s}$, wheel pressure of $F=700000 \mathrm{~Pa}$, the coefficient of rolling friction $\alpha=0.02$, and ALN $n=1000000$, the calculation results of $\mathrm{RD}$ for different temperatures of $15^{\circ} \mathrm{C}, 40^{\circ} \mathrm{C}$, and $60^{\circ} \mathrm{C}$ are shown in Table 7.

In Table 7 and Figure 10, the RD increased with the growth of temperature. The $\mathrm{RD}$ appeared to be linearly increasing from $2.65 \mathrm{~mm}$ to $4.92 \mathrm{~mm}$ when the pavement temperature increased from $15^{\circ} \mathrm{C}$ to $50^{\circ} \mathrm{C}$. However, the growth of the 
TABLE 5: Relationship between rutting depth and the cumulative number of equivalent axle loads.

\begin{tabular}{|c|c|c|c|c|c|c|}
\hline \multirow{2}{*}{ Cumulative number of equivalent axle loads } & \multicolumn{3}{|c|}{$\mathrm{RD}$ of structure $\mathrm{A}(\mathrm{mm})$} & \multicolumn{3}{|c|}{$\mathrm{RD}$ of structure $\mathrm{B}(\mathrm{mm})$} \\
\hline & FEM & This work & Error $(\%)$ & FEM & This work & Error $(\%)$ \\
\hline 100 & 0.008 & 0.0082 & 2.50 & 0.204 & 0.205 & 0.49 \\
\hline 1000 & 0.145 & 0.147 & 1.38 & 0.920 & 0.929 & 0.98 \\
\hline 10000 & 0.660 & 0.665 & 0.75 & 2.032 & 2.061 & 1.43 \\
\hline 100000 & 1.388 & 1.454 & 4.76 & 3.590 & 3.634 & 1.23 \\
\hline 1000000 & 2.652 & 2.703 & 1.92 & 6.030 & 6.280 & 4.15 \\
\hline 3000000 & 4.750 & 4.758 & 0.17 & 8.692 & 8.734 & 0.48 \\
\hline 6000000 & 6.320 & 6.517 & 2.14 & 9.750 & 9.977 & 2.33 \\
\hline
\end{tabular}

TABLE 6: Rutting depth of asphalt pavement structure A for different wheel pressures.

\begin{tabular}{|c|c|c|c|c|c|c|}
\hline \multirow{2}{*}{$\begin{array}{l}\text { Wheel pressure } \\
(\mathrm{MPa})\end{array}$} & \multicolumn{6}{|c|}{$\mathrm{RD}(\mathrm{mm})$} \\
\hline & 0.7 & 0.8 & 0.9 & 1.0 & 1.1 & 1.2 \\
\hline FEM & 8.22 & 11.52 & 15.01 & 17.18 & 20.64 & 22.45 \\
\hline This work & 8.52 & 12.09 & 15.40 & 18.02 & 21.17 & 23.04 \\
\hline Error (\%) & 3.65 & 4.95 & 2.60 & 4.89 & 2.57 & 2.63 \\
\hline
\end{tabular}

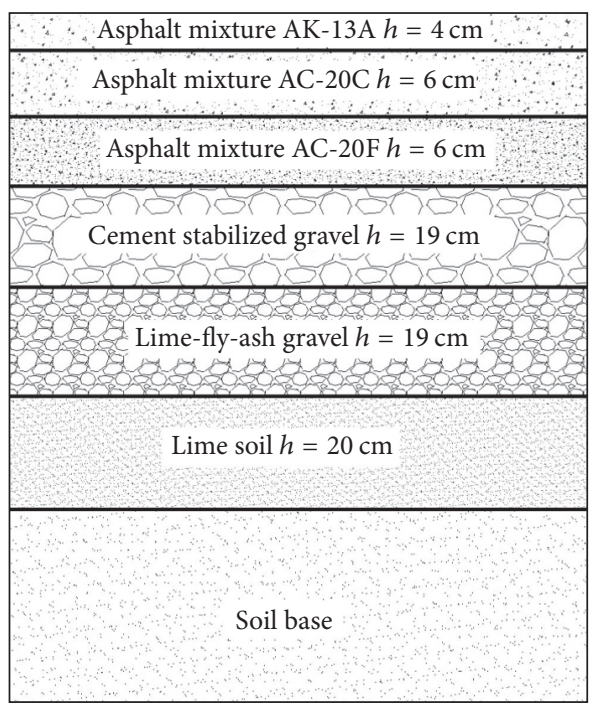

FIGURE 6: Asphalt pavement structure with multiasphaltic layers (structure (A)).

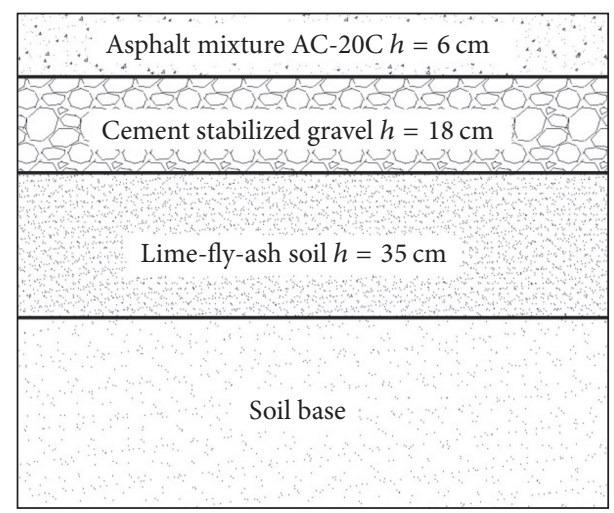

FIGURE 7: Asphalt pavement structure with single asphaltic layer (structure (B)).
$\mathrm{RD}$ is soaring at an increasing speed which turned to be a nonlinear form when the pavement temperature is greater than $50^{\circ} \mathrm{C}$. In high-temperature area, the temperature of asphalt pavement often changes from $15^{\circ} \mathrm{C}$ to $60^{\circ} \mathrm{C}$. The line slope between $50^{\circ} \mathrm{C}$ and $60^{\circ} \mathrm{C}$ is sharper than that between $15^{\circ} \mathrm{C}$ and $50^{\circ} \mathrm{C}$ in Figure 10. That is to say, the effect of high temperature on $\mathrm{RD}$ is evident compared with that of low temperature. Therefore, the special attention should be paid to the material design to prevent formation of rutting under high-temperature condition.

5.5. Effect of Vehicle Speed. For temperature of $60^{\circ} \mathrm{C}$, wheel pressure of $F=700000 \mathrm{~Pa}$, the coefficient of rolling friction $\alpha=0.02$, and ALN $n=1000000$, the calculation results for the rutting depth of asphalt pavement $B$ at different vehicle speeds are shown in Figure 11.

Figure 11 shows the relationship between vehicle speed and $\mathrm{RD}$. It can be seen that RD decreases nonlinearly with vehicle speed increasing overall. Figure 12 shows the percentage of decline in rutting depth at different speeds range. It can be seen that this kind of decreasing trend is gentle with the vehicle speed increasing. Conversely, the rutting depth will be more evident when the vehicle speed of vehicle becomes slow. In practice, at some special road sections such as road section with large longitudinal slope and intersection of roads, the vehicle travels at a relatively low speed which makes loading time relatively increased. As we know, the material of asphalt pavement is viscoelastic and depends partly on load time. Therefore, the RD develops accordingly.

\section{Conclusions}

The solution of Burgers model is employed and simplified, which makes the residual strain only depend on the applied stress. Then, the governing equation for dynamic response of pavement was established and a semianalytical solution related to the stress state of asphalt pavement was obtained. 


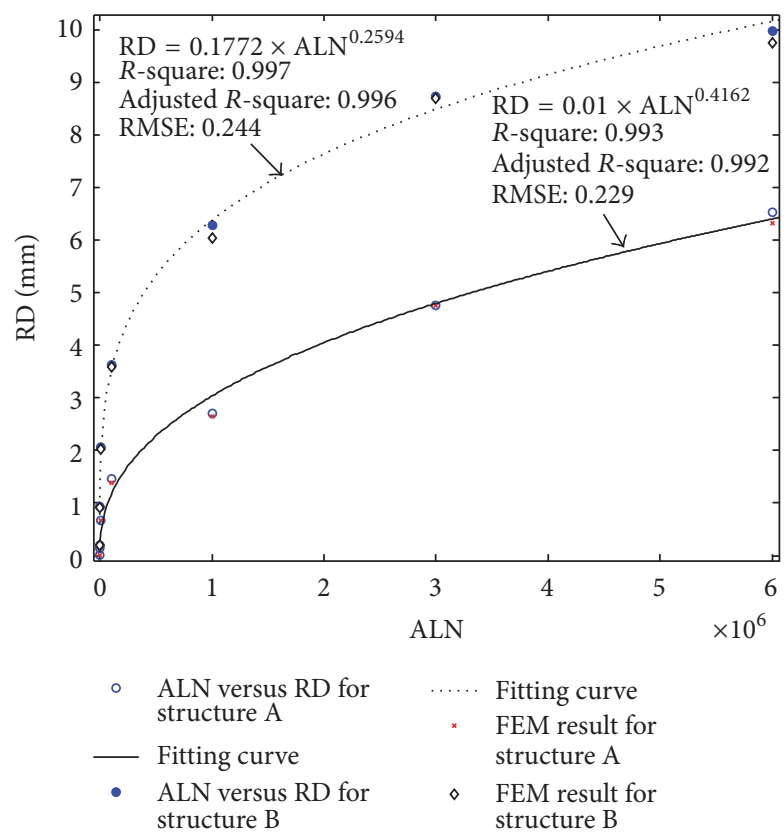

(a)

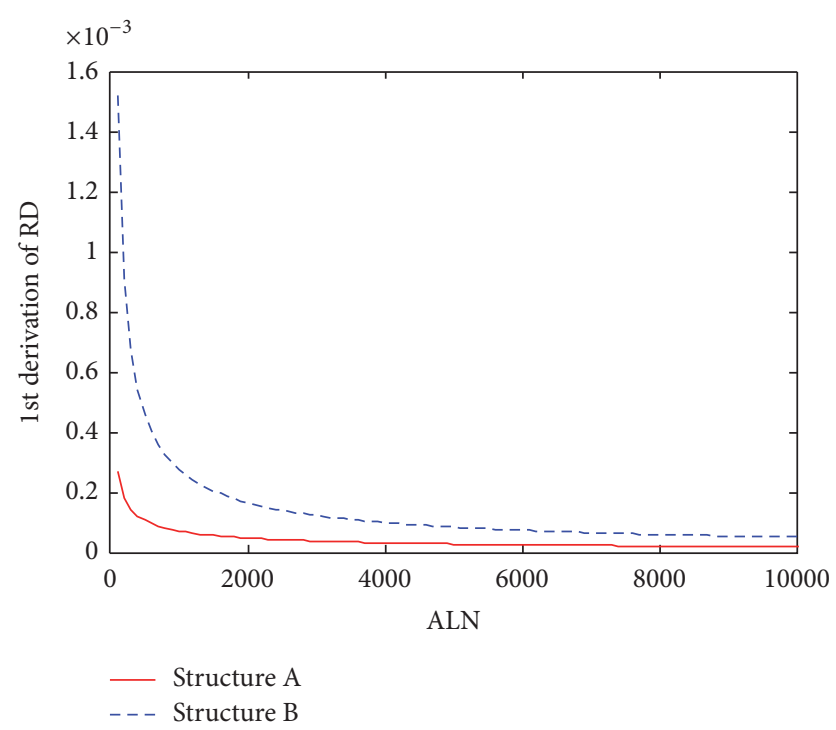

(b)

FIGURE 8: Effect of ALN on rutting depth of asphalt pavements A and $\mathrm{B}$.

An explicit expression was presented and validated to calculate rutting depth of asphalt pavement through incorporating the dynamic stress solution, simplified Burgers model solution, and time hardening model. Compared with the FEM method, the calculation error was less than $5 \%$, which proved the method proposed to be feasible. Through parameters analysis, the following additional conclusions can be drawn.

(1) The axle load number (ALN) makes the rutting depth increase in a power function manner and the rutting depth (RD) increased rapidly with the increase of ALN at the initial stage. As far as the application is concerned, the relation between $\mathrm{RD}$ and ALN can effectively predict the

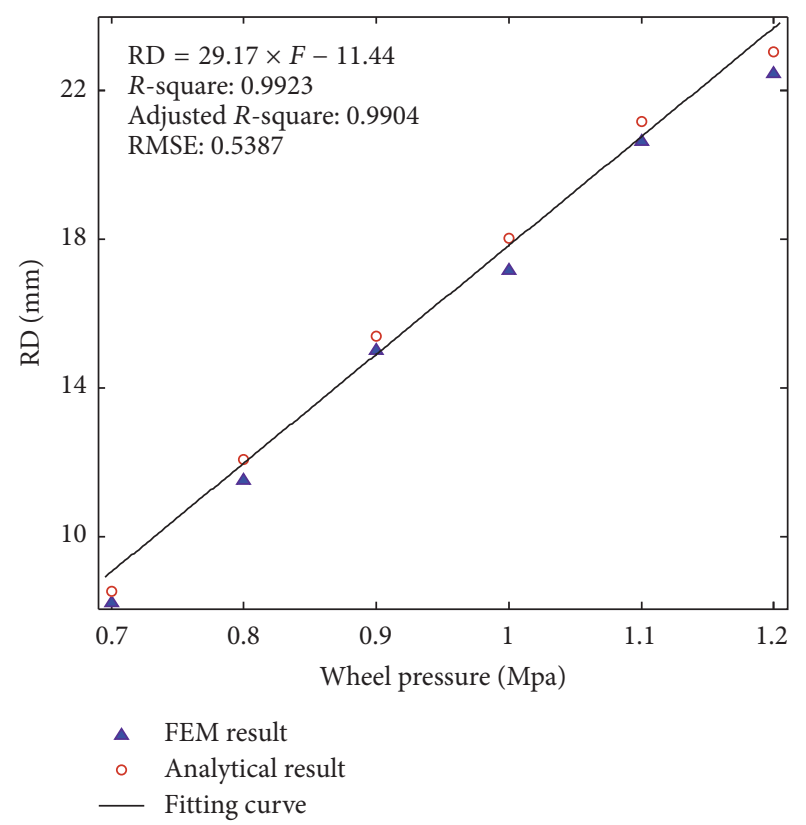

FIgURE 9: RD of asphalt pavement structure A for different wheel pressures.

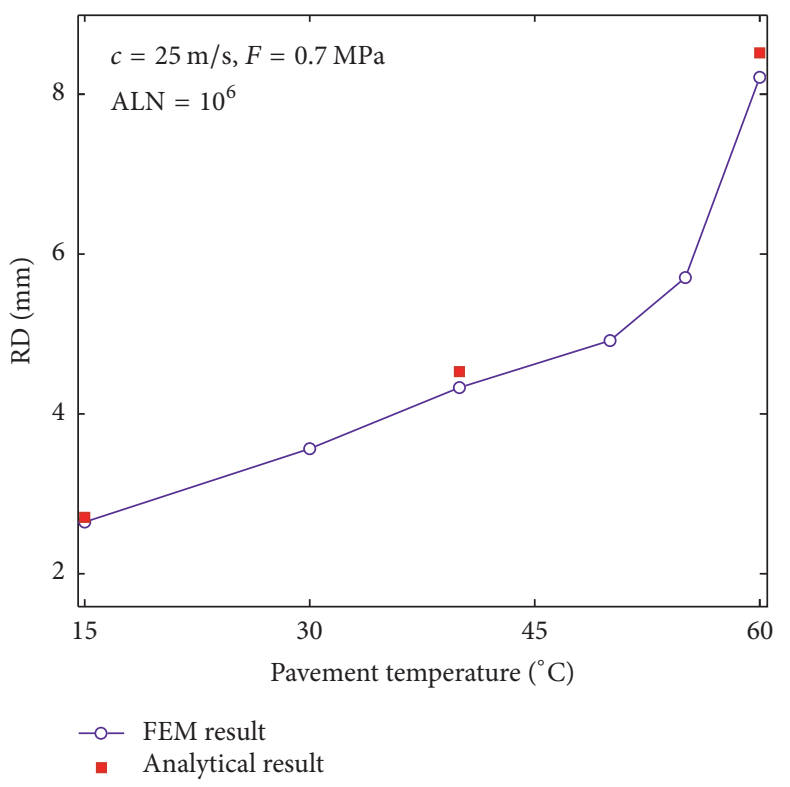

FIGURE 10: RD versus pavement temperature.

trend of the rutting depth and provide the information that more attention should be paid to the early period after the pavement is opened to traffic in the preventive maintenance of the highway.

(2) $\mathrm{RD}$ is sensitive to the magnitude of wheel pressure and increases approximately linearly. It indicates the heavy traffic load (wheel pressure) will expedite formation of asphalt pavement rutting. In the design stage of the highway pavement, the effect of overload on the pavement surface should be considered in terms of heavy haul vehicles. 
TABLE 7: Rutting depth of asphalt pavement at different temperature.

\begin{tabular}{|c|c|c|c|c|c|c|}
\hline \multirow{2}{*}{ Temperature $\left({ }^{\circ} \mathrm{C}\right)$} & \multicolumn{6}{|c|}{$\mathrm{RD}(\mathrm{mm})$} \\
\hline & 15 & 30 & 40 & 50 & 55 & 60 \\
\hline FEM & 2.65 & 3.57 & 4.33 & 4.92 & 5.71 & 8.22 \\
\hline This work & 2.70 & - & 4.53 & - & - & 8.52 \\
\hline
\end{tabular}

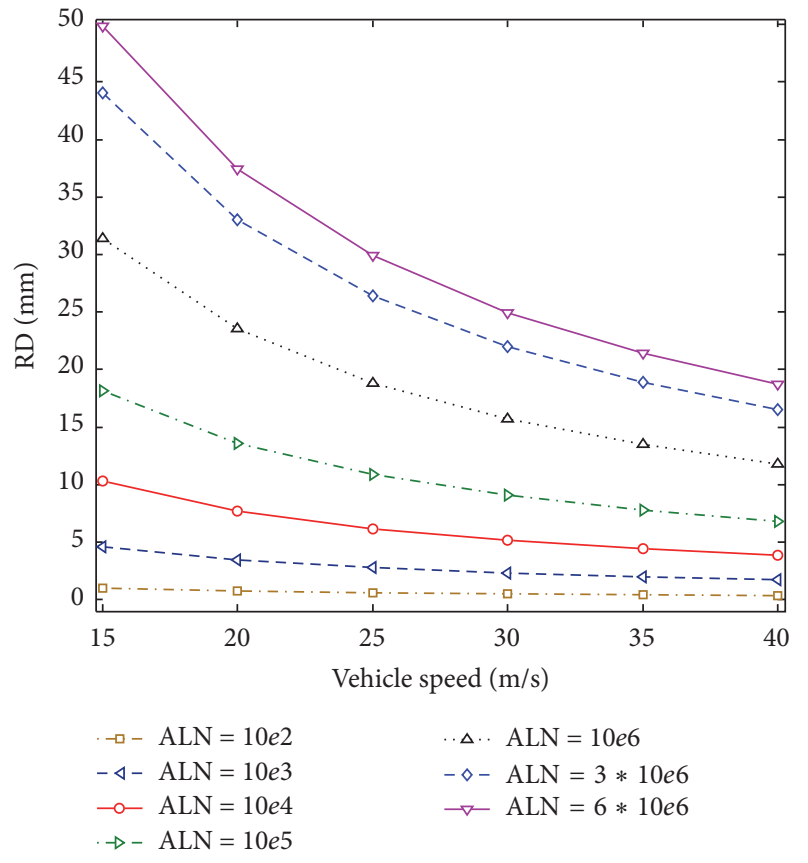

FIGURE 11: Rutting of asphalt pavement B versus vehicle speed.

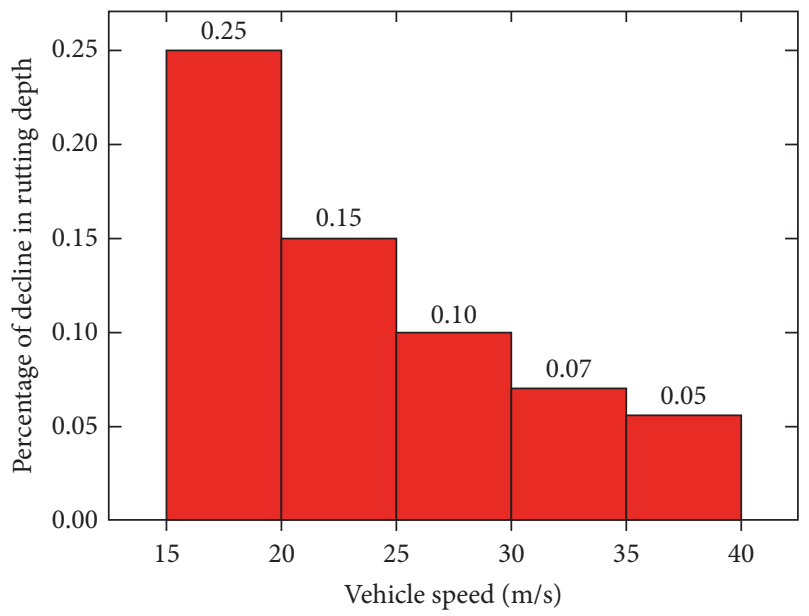

FIGURE 12: Decline percentage of rutting depth at different speeds range.

(3) The RD appeared to be linearly increasing when the temperature is less than $50^{\circ} \mathrm{C}$. However, the growth of the $\mathrm{RD}$ is soaring at an increasing speed which turned to be a nonlinear form when the pavement temperature is greater than $50^{\circ} \mathrm{C}$. The effect of high temperature on $\mathrm{RD}$ is evident compared with that of low temperature and the $\mathrm{RD}$ of asphalt pavement will be more evident for slow speed of vehicle.

(4) The solution presented in this paper can provide theoretical technical support for predicting rutting of asphalt pavement and can be beneficial for dealing with the rutting of asphalt pavement. In practice, the attention should be paid to the factors such as wheel pressure of vehicle, ALN, pavement temperature, and vehicle speed to prevent and delay the rutting formation.

\section{Notations}

$t_{0}: \quad$ Loading time of the stress (s)

$E_{1}$ : $\quad$ Stiffness parameter of spring 1 of the Burgers model $(\mathrm{Pa})$

$E_{2}$ : Stiffness parameter of spring 2 of the Burgers model $(\mathrm{Pa})$

$\alpha: \quad$ Coefficient of consolidation (-)

$p: \quad$ Interstitial hydraulic pressure $(\mathrm{Pa})$

$\eta_{1}$ : Viscosity parameter of damper 1 of the Burgers model (Pa.s)

$\eta_{2}$ : Viscosity parameter of damper 2 of the Burgers model (Pa.s)

$\varepsilon_{1}: \quad$ Strain of spring 1 of the Burgers model (-)

$\varepsilon_{2}$ : $\quad$ Strain of spring 2 and dashpot 2 of the Burgers model (-)

$\varepsilon_{3}: \quad$ Strain of dashpot 1 of the Burgers model (-)

$\varepsilon_{x z}: \quad$ Strain in the $x z$ plane $(-)$

$\sigma: \quad$ Stress $(\mathrm{Pa})$

v: $\quad$ Poisson's ratio (-)

$\dot{\sigma}: \quad$ First derivative of stress (-)

$\ddot{\sigma}: \quad$ Second derivative of stress (-)

$\dot{\varepsilon}: \quad$ First derivative of strain $(-)$

$\ddot{\varepsilon}: \quad$ Second derivative of strain (-)

E: $\quad$ Elasticity modulus $(\mathrm{Pa})$

$\varepsilon_{v}: \quad$ Volumetric strain (-)

$\varepsilon_{r}: \quad$ The recovery strain (-)

$\Delta \varepsilon: \quad$ The residual strain (-)

$F$ : $\quad$ Moving traffic load $(\mathrm{Pa})$

2L: $\quad$ The distribution cycle of moving traffic load $(\mathrm{m})$

$c: \quad$ The velocity of moving traffic load $(\mathrm{m} / \mathrm{s})$

$t: \quad$ Moving time (s)

$x: \quad$ The position of moving traffic load $(\mathrm{m})$

2l: $\quad$ The width of moving traffic load (m)

I: $\quad$ Imaginary component (-)

$\omega_{x}, \omega_{z}$ : Velocities of solid particle in $x$ and $z$ directions, respectively $\left(\mathrm{m} \cdot \mathrm{s}^{-1}\right)$

$\omega_{m}: \quad$ Angular velocity $\left(\mathrm{s}^{-1}\right)$

$\rho_{s}: \quad$ Mass of solid particles $(\mathrm{kg})$

$G$ : $\quad$ Shear modulus $(\mathrm{Pa})$ 
$G^{*}: \quad$ The dynamic shear modulus of the solid material (Pa)

$N: \quad$ Poisson's ratio (-)

$\sigma_{x x}, \sigma_{z z}$ : Total normal stress in $x$ and $z$ directions, respectively $(\mathrm{Pa})$

$\sigma_{x x}^{\prime}, \sigma_{z z}^{\prime}$ : Effective normal stress in $x$ and $z$ directions, respectively $(\mathrm{Pa})$

$\varepsilon_{x x}, \varepsilon_{z z}$ : The normal strains along $x$ and $z$ coordinates, respectively (-)

$\varepsilon_{v}: \quad$ Volume strain (-)

$\tau_{x z}: \quad$ Elastic shear stress $(\mathrm{Pa})$

$x, z: \quad$ Space coordinates in $x$ and $z$ directions, respectively $(\mathrm{m})$

$\xi_{x}, \xi_{z}$ : The displacements along the $x$ and $z$ directions, respectively (-)

$\delta: \quad$ Damping ratio of material (-)

$G_{i}^{*}: \quad$ The dynamic shear modulus of the $i$ th pavement layer $(\mathrm{Pa})$

$v_{i}: \quad$ Poisson's ratio of the $i$ th pavement layer (-)

$\xi_{i x}, \xi_{i z}$ : The displacements along the $x$ and $z$ directions of the $i$-th pavement layer, respectively (-)

$m: \quad$ Integer number (-)

$H_{i}$ : $\quad$ Distance of the $i$ th pavement layer bottom to top of surface course $(\mathrm{m})$

$\tau_{i x z}: \quad$ Elastic shear stress of the $i$ th pavement layer $(\mathrm{Pa})$

$\sigma_{i x}, \sigma_{i z}$ : Total normal stress of the $i$ th pavement layer in $x$ and $z$ directions, respectively $(\mathrm{Pa})$

$q_{i j}: \quad$ The roots of the 4 th-order polynomials in (24) (-)

$n: \quad$ The number of standard axle load cycles (-)

$B: \quad$ Related to the parameters of the asphalt pavement $(-)$.

\section{Conflicts of Interest}

The authors declare that they have no conflicts of interest.

\section{Acknowledgments}

This research has been supported by the National Natural Science Foundation of China (Grants nos. 51248006 and 51308554), the Special Financial Grant from the China Postdoctoral Science Foundation (Grant no. 2013T60865), and the Guizhou Transportation Science and Technology Foundation (Grant no. 2013-121-013) to the corresponding author. The research is also supported by the Guizhou Science and Technology Department Foundation (Grant no. 20132167), the Hunan Transportation Science and Technology Foundation (Grant no. 201237), and the Central South University Graduate Student Innovation Fund Project (2015zzts062).

\section{References}

[1] H.-C. Dan, P. Xin, L. Li, L. Li, and D. Lockington, "Boussinesq equation-based model for flow in the drainage layer of highway with capillarity correction," Journal of Irrigation and Drainage Engineering, vol. 138, no. 4, pp. 336-348, 2012.

[2] H.-C. Dan, P. Xin, L. Li, and L. Li, "Improved boussinesq equation-based model for transient flow in a drainage layer of highway: Capillary correction," Journal of Irrigation and Drainage Engineering, vol. 139, no. 12, pp. 1018-1027, 2013.
[3] H.-C. Dan, L.-H. He, J.-F. Zou, L.-H. Zhao, and S.-Y. Bai, "Laboratory study on the adhesive properties of ice to the asphalt pavement of highway," Cold Regions Science and Technology, vol. 104-105, pp. 7-13, 2014.

[4] R. K. Abu Al-Rub, M. K. Darabi, C.-W. Huang, E. A. Masad, and D. N. Little, "Comparing finite element and constitutive modelling techniques for predicting rutting of asphalt pavements," International Journal of Pavement Engineering, vol. 13, no. 4, pp. 322-338, 2012.

[5] Q. Xu and L. N. Mohammad, "Modeling asphalt pavement rutting under accelerated testing," Road Materials and Pavement Design, vol. 9, no. 4, pp. 665-687, 2008.

[6] A. R. Archilla and S. Madanat, "Development of a pavement rutting model from experimental data," Journal of Transportation Engineering, vol. 126, no. 4, pp. 291-299, 2000.

[7] S. F. Said, H. Hakim, E. Oscarsson, and M. Hjort, "Prediction of flow rutting in asphalt concrete layers," International Journal of Pavement Engineering, vol. 12, no. 6, pp. 519-532, 2011.

[8] J. Judycki, "Non-linear viscoelastic behaviour of conventional and modified asphaltic concrete under creep," Materials and Structures, vol. 25, no. 2, pp. 95-101, 1992.

[9] W. G. Wong, H. Han, G. He, K. C. P. Wang, and W. Lu, "Rutting response of hot-mix asphalt to generalized dynamic shear moduli of asphalt binder," Construction and Building Materials, vol. 18, no. 6, pp. 399-408, 2004.

[10] M. Zbikowski, D. Makarov, and V. Molkov, "Numerical simulations of large-scale detonation tests in the RUT facility by the LES model," Journal of Hazardous Materials, vol. 181, no. 1-3, pp. 949-956, 2010.

[11] A. Eddhahak-Ouni, A. Dony, and J. Colin, "Prediction of the rutting potential of bituminous binders using a stochastic approach," Road Materials and Pavement Design, vol. 13, no. 1, pp. 38-48, 2012.

[12] E. Coleri, J. T. Harvey, K. Yang, and J. M. Boone, "Micromechanical investigation of open-graded asphalt friction courses' rutting mechanisms," Construction and Building Materials, vol. 44, pp. 25-34, 2013.

[13] S. P. A. Narayan, D. N. Little, and K. R. Rajagopal, "Analysis of rutting prediction criteria using a nonlinear viscoelastic model," Journal of Materials in Civil Engineering, vol. 27, no. 3, Article ID 04014137, 2015.

[14] J. J. Halvorson, D. K. McCool, L. G. King, and L. W. Gatto, "Soil compaction and over-winter changes to tracked-vehicle ruts, Yakima Training Center, Washington," Journal of Terramechanics, vol. 38, no. 3, pp. 133-151, 2001.

[15] M. Novak, B. Birgisson, and R. Roque, "Near-surface stress states in flexible pavements using measured radial tire contact stresses and ADINA," Computers and Structures, vol. 81, no. 8-11, pp. 859-870, 2003.

[16] B. B. Budkowska and J. Yu, "Mitigation of short term rutting by interlocking layer developed around a geogrid-sensitivity analysis," Computers and Geotechnics, vol. 30, no. 1, pp. 61-79, 2002.

[17] P. Kettil, B. Lenhof, K. Runesson, and N.-E. Wiberg, "Simulation of inelastic deformation in road structures due to cyclic mechanical and thermal loads," Computers and Structures, vol. 85, no. 1-2, pp. 59-70, 2007.

[18] C. Chazallon, G. Koval, P. Hornych, F. Allou, and S. Mouhoubi, "Modelling of rutting of two flexible pavements with the shakedown theory and the finite element method," Computers and Geotechnics, vol. 36, no. 5, pp. 798-809, 2009. 
[19] D. V. Ramsamooj, J. Ramadan, and G. S. Lin, "Model prediction of rutting in asphalt concrete," Journal of Transportation Engineering, vol. 124, no. 5, pp. 448-456, 1998.

[20] Z. L. Lu and L. J. Sun, "Research on Rutting Prediction of Asphalt Pavement," Journal of Tong-ji University (Natural Science), vol. 35, no. 11, pp. 1476-1480, 2007.

[21] F. Morea, R. Marcozzi, and G. Castaño, "Rheological properties of asphalt binders with chemical tensoactive additives used in Warm Mix Asphalts (WMAs)," Construction and Building Materials, vol. 29, pp. 135-141, 2012.

[22] H.-C. Dan, L.-H. He, L.-H. Zhao, and J.-Q. Chen, "Coupled hydro-mechanical response of saturated asphalt pavement under moving traffic load," International Journal of Pavement Engineering, vol. 16, no. 2, pp. 125-143, 2015.

[23] N. Saboo and P. Kumar, "A study on creep and recovery behavior of asphalt binders," Construction and Building Materials, vol. 96, pp. 632-640, 2015.

[24] A. Verruijt, An Introduction to Soil Dynamics, Springer, Berlin, Germany, 2010.

[25] S. M. Fielding, P. Sollich, and M. E. Cates, "Aging and rheology in soft materials," Journal of Rheology, vol. 44, no. 2, pp. 323-369, 2000.

[26] A. Karlström and A. Boström, "An analytical model for traininduced ground vibrations from railways," Journal of Sound and Vibration, vol. 292, no. 1-2, pp. 221-241, 2006.

[27] M. F. M. Hussein and H. E. M. Hunt, "A numerical model for calculating vibration due to a harmonic moving load on a floating-slab track with discontinuous slabs in an underground railway tunnel," Journal of Sound and Vibration, vol. 321, no. 1-2, pp. 363-374, 2009.

[28] D. D. Theodorakopoulos, "Dynamic analysis of a poroelastic half-plane soil medium under moving loads," Soil Dynamics and Earthquake Engineering, vol. 23, no. 7, pp. 521-533, 2003.

[29] ABAQUS, ABAQUS analysis user's manual, version 6.10, Habbit, Karlsson \& Sorenson Inc, Pawtucket, RI, USA, 2006.

[30] A. Szydlo and P. Mackiewicz, "Asphalt mixes deformation sensitivity to change in rheological parameters," Journal of Materials in Civil Engineering, vol. 17, no. 1, pp. 1-9, 2005.

[31] X. J. An, Analysis of affect factors on high temperature deformation of asphalt mixture based on the Burgers model [Ph.D. thesis], Ji Lin University, 2011.

[32] F. Wang, Calculation of asphalt pavement rutting based on rheological constitutive model and dynamic finite element analysis, Chongqing Jiaotong University, 2009. 


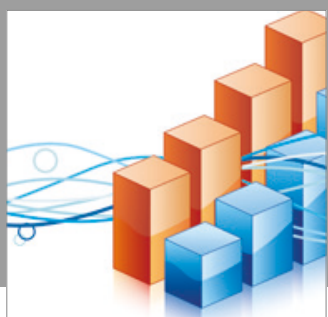

Advances in

Operations Research

vatersals

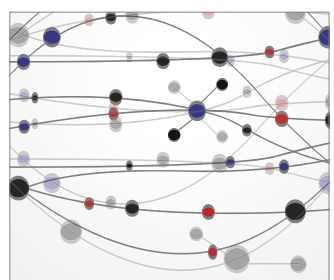

\section{The Scientific} World Journal
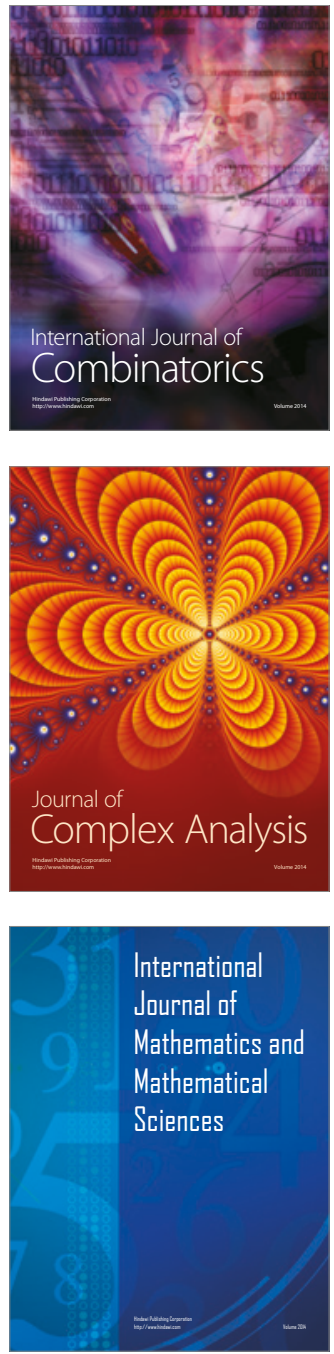
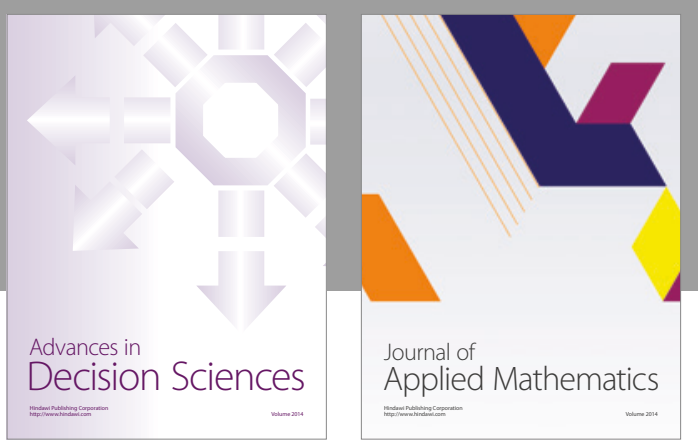

Algebra

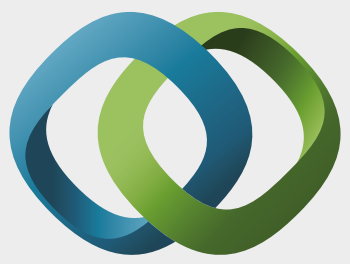

\section{Hindawi}

Submit your manuscripts at

https://www.hindawi.com
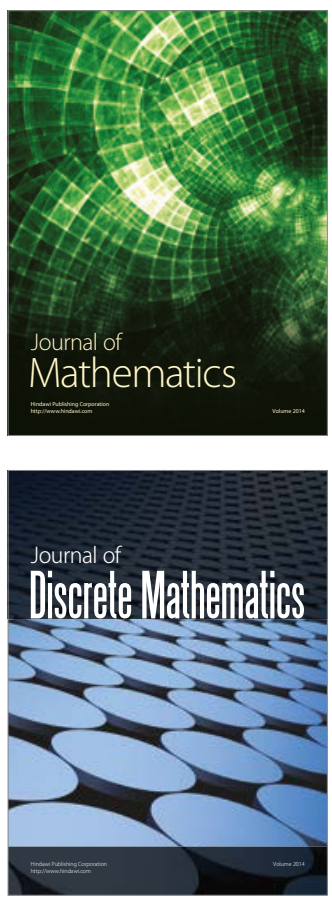

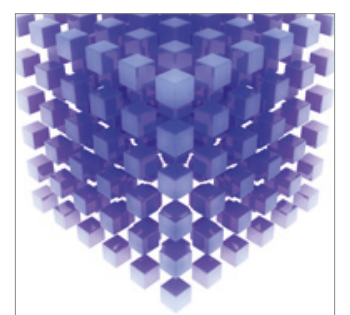

Mathematical Problems in Engineering
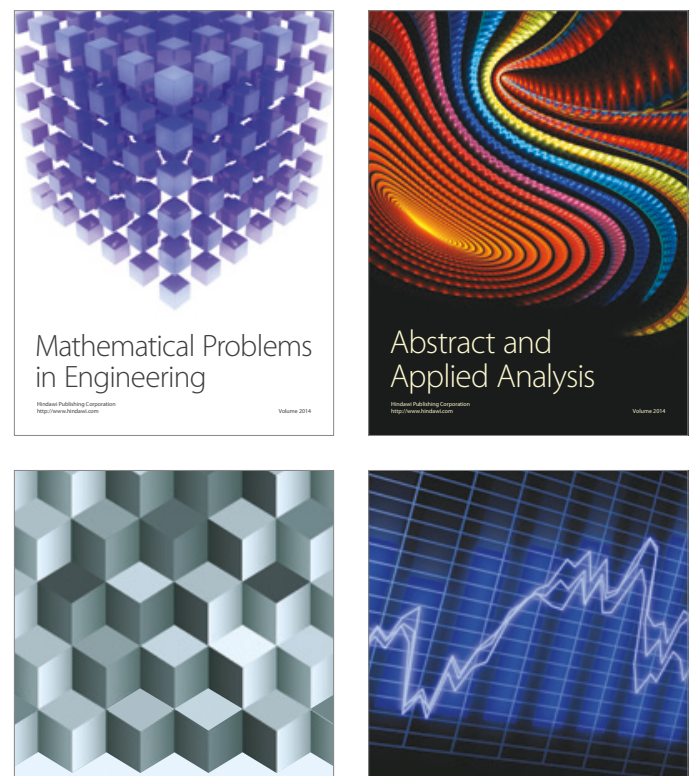

Journal of

Function Spaces

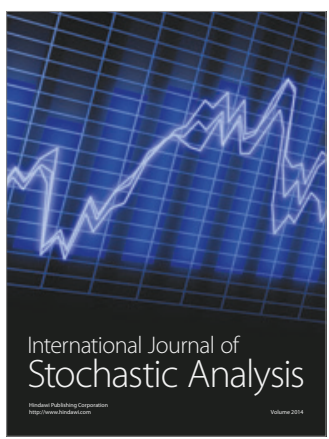

Probability and Statistics
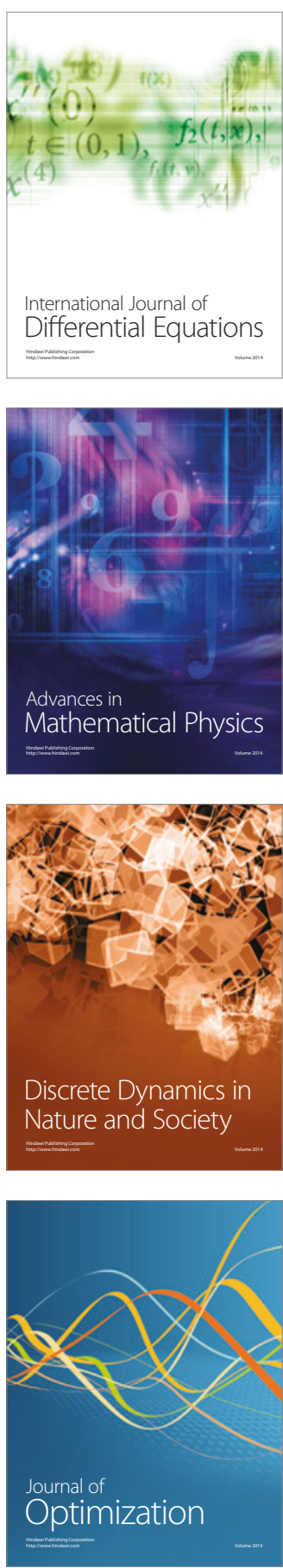